\title{
CDK4/6 Inhibitor LEE011 Is a Potential Radiation-sensitizer in Head and Neck Squamous Cell Carcinoma: An In Vitro Study
}

\author{
TZONG-SHYUAN TAI ${ }^{1}$, PAI-MEI LIN ${ }^{2}$, CHING-FANG WU ${ }^{2,3}$, SHIH-KAI HUNG ${ }^{4}$, \\ CHUNG-I HUANG ${ }^{5}$, CHIH-CHUN WANG ${ }^{6}$ and YU-CHIEH SU 7,8 \\ ${ }^{1}$ Department of Medical Research, E-Da Hospital, Kaohsiung, Taiwan, R.O.C.; \\ ${ }^{2}$ School of Medicine, I-Shou University, Kaohsiung, Taiwan, R.O.C.; \\ ${ }^{3}$ Division of Nephrology, E-Da Hospital, Kaohsiung, Taiwan, R.O.C.; \\ ${ }^{4}$ Department of Radiation Oncology, Dalin Tzu Chi Hospital, \\ Buddhist Tzu Chi Medical Foundation, ChiaYi, Taiwan, R.O.C.; \\ ${ }^{5}$ Department of Radiation Oncology, E-Da Cancer Hospital, Kaohsiung, Taiwan, R.O.C.; \\ ${ }^{6}$ Department of Otolaryngology, E-Da Hospital, Kaohsiung, Taiwan, R.O.C.; \\ ${ }^{7}$ Division of Hematology-Oncology, Department of Internal Medicine, \\ Kaohsiung Medical University Hospital, Kaohsiung, Taiwan, R.O.C.; \\ ${ }^{8}$ Faculty of Medicine, Kaohsiung Medical University, Kaohsiung, Taiwan, R.O.C.
}

\begin{abstract}
Background: Radiotherapy (RT) combined with a radiosensitizer represents an important treatment for head and neck squamous cell carcinoma (HNSCC). Only few chemotherapy agents are currently approved as radiosensitizers for targeted therapy. In this study, the potent cyclin-dependent kinase 4/6 (CDK4/6) inhibitor LEE011 was tested for potential to act as a radiosensitizer during $R T$. Materials and Methods: RT enhancement by LEE011 was assessed by in vitro clonogenic assay, flow cytometry, and western blot in a variety of HNSCC cell lines. The HNSCC cell line OML1 and its radiation-resistant clone OML1-R were used. Results: LEEO11 induced cell-cycle arrest in SCC4/SCC25 cells during the $G_{1} / M$ phase through inhibition of retinoblastoma protein phosphorylation. LEE011 enhanced the effects of radiation in OML1 cells and overcame radiation resistance in OML1-R cells. Conclusion: LEE011 is a potential radiosensitizer that can enhance the cytotoxic effects of RT. Clinical trials including LEE011 during RT for HNSCC should be considered.
\end{abstract}

Head and neck squamous cell carcinoma (HNSCC) is the sixth most common cancer worldwide, with more than

Correspondence to: Yu-Chieh Su, No.100, Tzyou 1st Road, Kaohsiung 807, Taiwan, R.O.C. Tel: +886 936380491, e-mail: hepatoma@gmail.com

Key Words: CDK4/6 inhibitor, LEE011, radiosensitization, head and neck cancer, radioresistance.
500,000 new cases and 300,000 deaths reported annually (1). The primary treatment for HNSCC is total surgical removal of the primary tumor and lymph nodes, and radiotherapy (RT) can also be considered as a treatment option for some patients. Radiosensitizers are promising agents that enhance injury to tumor tissue by accelerating DNA damage and producing free radicals. Since 1965, several chemotherapy agents have been used in the development of highly effective radiosensitizers (2), and data from the Meta-analysis of Chemotherapy in Head and Neck Cancer group has indicated improved overall survival associated with concurrent chemotherapy combined with RT (3), but more toxic effects were also observed. Cisplatin, carboplatin, and fluorouracil are currently the most common chemotherapy agents used as radiosensitizers during RT, while cetuximab is the only targeted therapy agent approved for use during RT for HNSCC (3).

The primary mechanism for radiation resistance in cancer cells is activation of the phosphoinositide 3-kinase (PI3K)/thymoma viral proto-oncogene 1(AKT)/the mammalian target of rapamycin (mTOR) pathway $(4,5)$, and blocking this pathway has been observed to increase sensitivity to radiation and improve the effect of RT on tumor cells. In previous studies, we used mTOR-specific and dual-targeted PI3K/AKT inhibitors in oral cancer cell lines and found that blocking PI3K/mTOR increased the radiation sensitivity of oral cancer cells and reversed radiation resistance in a resistant strain (OML1-R) (6-9). Notably, we identified modulation of checkpoint kinase 2 (CHK2) activity and the resulting effects on cyclin-dependent protein 

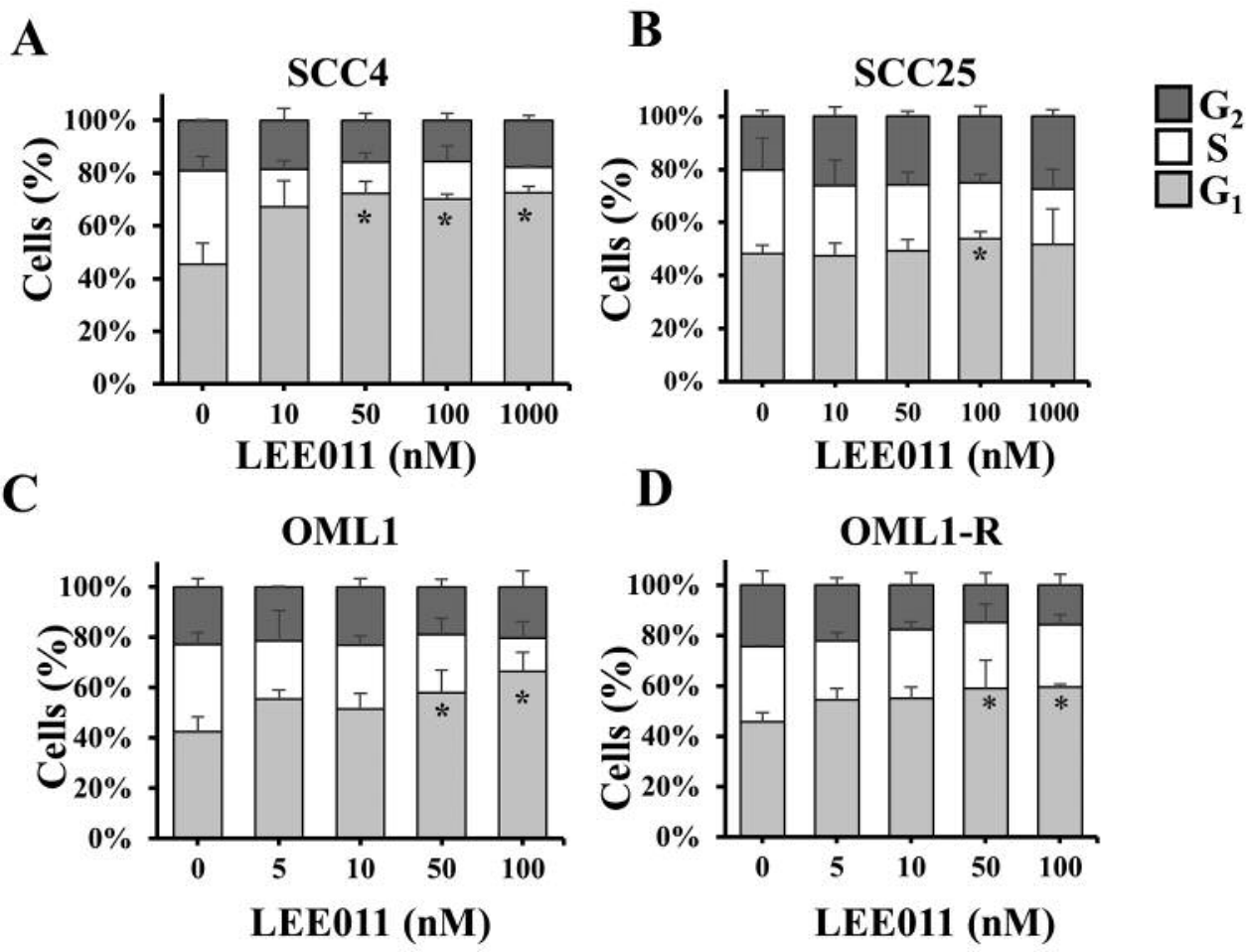

Figure 1. Treatment with LEE011 blocked cell-cycle progression. SCC4 (A), SCC25 (B), OML1 (C), and OML1-R (D) cells were treated with the indicated dose of LEE011 for $72 \mathrm{~h}$. Cells were harvested and stained with propidium iodide (PI) hypotonic buffer for cell-cycle analysis. The results of a Student's t-test comparing $G_{I}$ phase for each treatment and control are shown. Data represent the results of three independent experiments and is presented as the mean \pm the $S D$. *Significantly different at $p<0.05$.

kinase $1(\mathrm{CDK} 1) /$ cyclin B1 activity as a potential mechanism $(7,8)$ and we concluded that cell-cycle arrest is the major mechanism of radiation sensitization associated with $\mathrm{PI} 3 \mathrm{~K} / \mathrm{mTOR}$ inhibition. In the current study, we assessed the potential anti-tumor and radiation resistance-reversing effects of the CDK4/6 inhibitor LEE011, and explored the mechanism of cell-cycle arrest in radioresistance in HNSCC. This study provides important clinical information regarding development of radiosensitizer drugs for HNSCC therapy.

\section{Materials and Methods}

Reagents and chemicals. LEE011 was provided by the Novartis Pharmaceuticals Corporation (East Hanover, NJ, USA). Stock solutions were prepared in dimethylsulfoxide (DMSO) at $30 \mathrm{mM}$, stored at $-20^{\circ} \mathrm{C}$ until further use, and diluted in culture medium for each experiment.

Cell lines and culture. The human head and neck squamous cell carcinoma cell lines SCC4 and SCC25 derived from a squamous cell carcinoma of the tongue were purchased from the American Type Culture Collection (Manassas, VA, USA). The cells were cultured in Dulbecco's modified Eagle's medium/nutrient mixture F-12 (DMEM/F12) containing 10\% fetal bovine serum (FBS), penicillin-streptomycin $(10,000 \mathrm{U} / \mathrm{ml}$ penicillin and $10 \mathrm{mg} / \mathrm{ml}$ streptomycin), and $2 \mathrm{mM} \mathrm{L-glutamine(10).} \mathrm{OML1} \mathrm{and} \mathrm{OML1-R}$ cells were established as previously described (10) and maintained in RPMI1640 containing 10\% FBS, $1 \%$ penicillin-streptomycin, and $2 \mathrm{mM}$ L-glutamine. Cells were cultured in an incubator at $37^{\circ} \mathrm{C}$ under a humidified atmosphere of $5 \% \mathrm{CO}_{2}$ and $95 \%$ air.

Cell proliferation WST-1 assay. 4-(3-(4-iodophenyl)-2-(4-nitrophenyl)2H-5-tetrazolio)-1,3-benzene disulfonate (WST-1; Roche Applied Science, Indianapolis, IN, USA) colorimetric assays were performed according to the manufacturer's instructions. Briefly, $5 \times 10^{3}$ cells were seeded in 96-well plates for overnight culture, and then treated with either DMSO (vehicle) or LEE011 (5-1,000 nM) for 24 and $48 \mathrm{~h}$. Cell viability was measured after treatment by adding $10 \mu \mathrm{l}$ of WST-1 solution to the culture medium. After incubation for $4 \mathrm{~h}$ at $37^{\circ} \mathrm{C}$, the absorbance was measured by a microplate ELISA reader (Sunrise Absorbance Microplate Reader; Tecan, Männedorf, Switzerland) at a wavelength of $450 \mathrm{~nm}$ with a reference wavelength of $650 \mathrm{~nm}$.

Cell survival clonogenic assay. Cells were seeded at 100 cells per $10 \mathrm{~cm}$ dish for overnight culture. The cells were pre-treated with LEE011 (100 $\mathrm{nM}$ in DMSO) for $72 \mathrm{~h}$ before irradiation, then irradiated at $4 \mathrm{~Gy}$. The medium was replaced after $6 \mathrm{~h}$ and the cells were placed in an incubator at $37^{\circ} \mathrm{C}$ for further culture. After 7 days, colonies, defined as groups of $>50$ cells, were stained with $0.05 \%$ crystal violet and counted. Images for colony counting were acquired with a digital camera.

Cell-cycle profiling. Cells were seeded $1 \times 10^{4}$ cells $/ 10 \mathrm{~cm}$ dish for LEE011 (100 nM) treatment for $72 \mathrm{~h}$, then irradiated at $4 \mathrm{~Gy}$. 
A

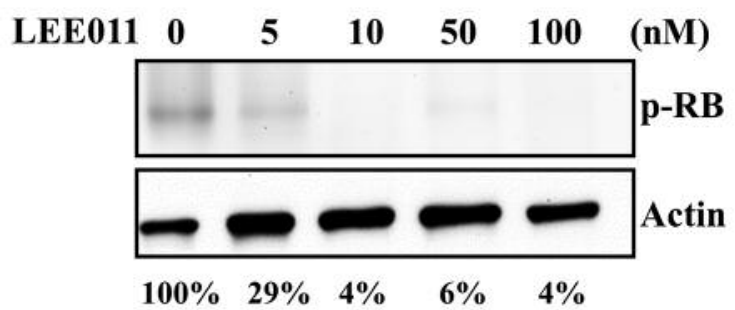

C

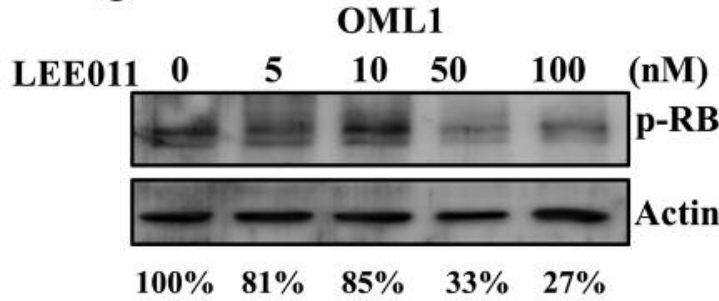

B SCC25

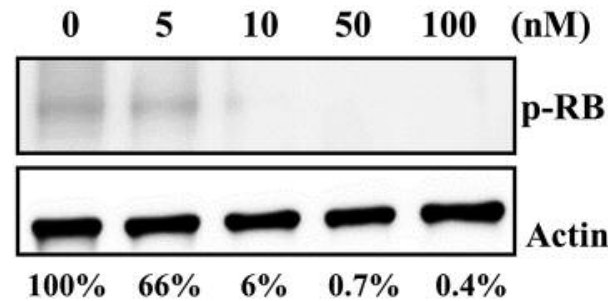

D

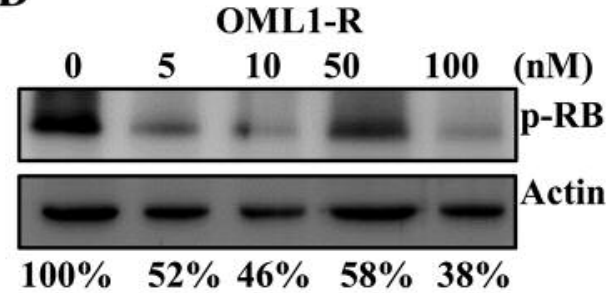

Figure 2. LEE011 inhibited retinoblastoma protein (RB) phosphorylation in head and neck squamous-cell carcinoma cells. SCC4 (A), SCC25 (B), OML1 $(C)$, and OML1-R (D) cells were treated with the indicated dose of LEE011 for $72 \mathrm{~h}$. Cell lysates were prepared and analyzed by western blot using antibodies to phosphor-RB ( $p-R B)$ and actin. The $p-R B$ band was normalized by actin and the percentage relative to that of the untreated control is shown.

Control cells were not irradiated. Cells were harvested following overnight culture and stained with hypotonic buffer $(1.5 \mu \mathrm{M}$ propidium iodide, P4170; Sigma-Aldrich, St. Louis, MO, USA) for at least $30 \mathrm{~min}$ at $4^{\circ} \mathrm{C}$. Cells were collected and analyzed by Accuri C6 (BD Bioscience, San Jose, CA, USA).

Western blotting. Cells were harvested and lysed with cell lysis buffer $(50 \mathrm{mM}$ Tris $\cdot \mathrm{HCl} \mathrm{pH} 7.4,150 \mathrm{mM} \mathrm{NaCl}, 2 \mathrm{mM}$ EDTA $\mathrm{pH}$ $8,0.5 \%$ Nonidet P-40, and $1 \%$ Triton-X 100) after treatment. Protein concentrations were measured using the Bio-Rad protein assay kit (Bio-Rad, Richmond, CA, USA). Forty micrograms of protein from each sample were separated by $12 \%$ sodium dodecyl sulphate-polyacrylamide gel electrophoresis and transferred to a polyvinylidene difluoride membrane (Millipore, Billerica, MA, USA). Membranes were incubated with the corresponding primary antibodies and secondary antibodies after blocking with non-fat dry milk for $1 \mathrm{~h}$. The following antibodies were used: anti-RB, antiphospho-RB(S780), anti-phospho-RB(S795) (all at 1:2,000; Cell Signaling, Beverly, MA, USA); and anti- $\beta$-actin $(1: 2,000$; Santa Cruz Biotechnology, Dallas, Tx, USA). Proteins were visualized using a chemiluminescence (ECL) detection kit (Millipore, Billerica, MA, USA) and all blots were quantified with ImageJ (National Institutes of Health, Bethesda, MD, USA).

Statistical analysis. All data are presented as the mean \pm standard deviation. Significance levels were calculated using Student's $t$-test and $p$-values of less than 0.05 were considered statistically significant.

\section{Results}

LEE011 arrested the cell cycle in human oral cancer cells. We investigated whether LEE011 can increase radiosensitivity of oral cancer cell lines by blocking cell-cycle progression. Four different HNSCC cell lines were treated with LEE011 and subjected to cell-cycle analysis. The G1 percentage increased from $40 \%$ to $70 \%$ following $10 \mathrm{nM}$ LEE011 treatment in SCC4 cells (Figure 1A). $\mathrm{G}_{1}$ arrest became statistically significant after $50 \mathrm{nM}$ LEE011 treatment in OML1 and OML1-R cells (Figure 1C and D). While SCC25 cells were more resistant to LEE011 inhibition, G1 arrest became statistically significant after $100 \mathrm{nM}$ LEE011 treatment in this cell line (Figure 1B). Together, these observations suggest that LEE011 can arrest the cell cycle in HNSCC cells.

LEE011 inhibited RB phosphorylation. We examined the phosphorylation status of RB following LEE011 treatment to confirm the inhibition of CDK4/6 activity by LEE011. LEE011 inhibited RB phosphorylation at $5 \mathrm{nM}$ in the four cell lines tested (Figure 2). RB phosphorylation was completely inhibited in SCC4 and SCC25 cells following treatment with 10-50 nM LEE011 (Figure 2A and B) and RB phosphorylation was inhibited up to $70 \%$ in OML1 and OML1-R cells following treatment with $100 \mathrm{nM}$ LEE011 (Figure 2C and D). LEE011 treatment led to a significant difference in RB phosphorylation, especially in the SCC4 line. These data indicate that LEE011 blocks cell-cycle progression through RB inhibition of phosphorylation.

LEE011 did not induce cytotoxicity in human oral cancer cells. We used the WST-1 method to examine the survival 
A

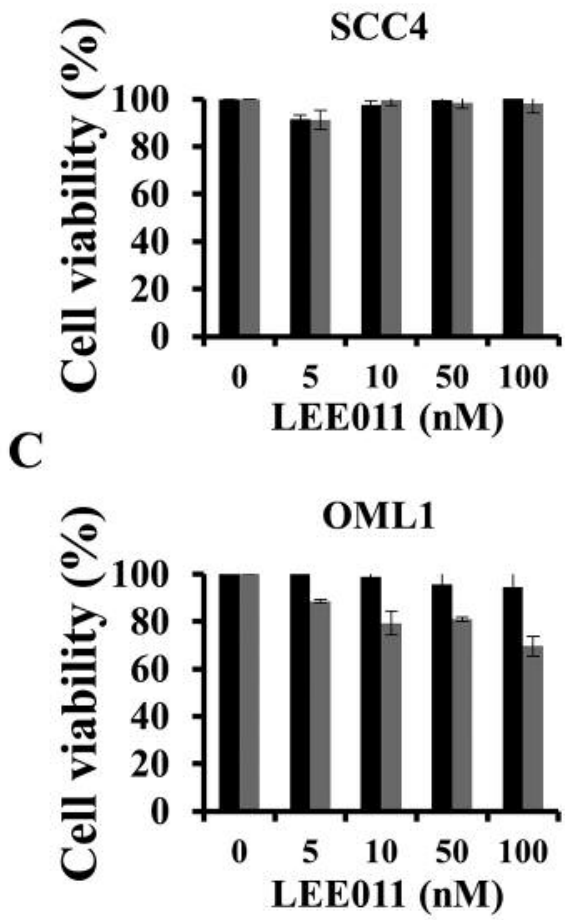

B

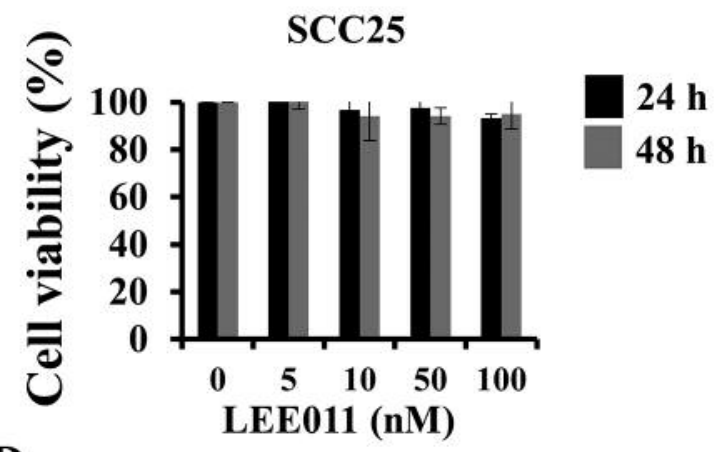

D

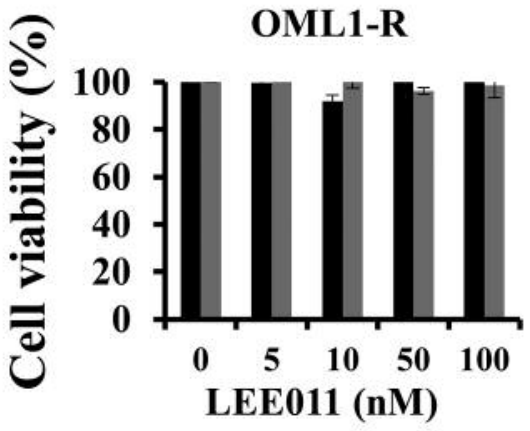

Figure 3. LEE011 induced cell cytotoxicity in head and neck squamous-cell carcinoma cells. SCC4 (A), SCC25 (B), OML1 (C), and OML1-R (D) cells were treated with the indicated dose of LEE011 for 24 and $48 \mathrm{~h}$. Cell viability was examined by the WST-1 assay.

rate of head and neck cancer cells treated with LEE011 at different concentrations. LEE011 did not induce cell toxicity at concentrations up to $100 \mathrm{nM}$ in any of the four cell lines at $24 \mathrm{~h}$ and there was no apparent inhibition of cell survival after treatment for $48 \mathrm{~h}$ (Figure 3). A slight decrease in cell viability was seen in OML1 cells after $100 \mathrm{nM}$ LEE011 treatment, but this did not reach statistical significance (Figure 3C). These data indicate that LEE011 did not induce cell cytotoxicity in human oral cancer cell lines.

The effects of LEE011 combined with RT on OML1 and OML1-R cell lines. While LEE011 blocks cell-cycle progression, it does not induce cell cytotoxicity. Our previous studies suggested that cell-cycle arrest by $\mathrm{PI} 3 \mathrm{~K} / \mathrm{mTOR}$ inhibitors increases radiosensitivity in human oral cancer cell lines $(7,8)$. Therefore, we examined the effects of LEE011 on radiosensitization in OML1, with the radioresistant cell line OML1-R as a control. OML1 and OML1-R cells were irradiated with $4 \mathrm{~Gy}$ alone or in combination with LEE011 and colony formation and cell proliferation effects were evaluated by clonogenic and WST1 proliferation assays, respectively (Figure 4). Radiation alone did not affect colony formation in the radioresistant cell line OML1-R; however, radiation combined with
LEE011 reduced colony formation in these cells (Figure 4A and $\mathrm{B}$ ). The WST-1 proliferation assay showed there to be a significant decrease in proliferation of OML1-R cells when treated with RT combined with LEE011 (Figure 4C). These data suggest that LEE011 might supplement RT to achieve radiosensitization.

RT with LEE011 blocked cell-cycle progression. The decrease of proliferation and clonogenic formation after LEE011 combined with RT suggests that the combined treatment blocks cell-cycle progression. We found that the percentage of OML1 cells in the $\mathrm{G}_{1}$ phase increased from $50 \%$ to $70 \%$ after treatment with LEE011 and RT (Figure 5A). A similar effect was seen in radioresistant OML1-R cells, in which the G1 percentage increased $54 \%$ to $65 \%$ following treatment (Figure 5B).

$R T$ with LEE011 blocked RB phosphorylation. The effect of combined LEE011 and RT treatment on the cell cycle may be due to a loss of CDK4/6 activity. We measured RB phosphorylation following LEE011 and RT treatment to examine CDK4/6 activity. Compared to the untreated control, combined treatment with LEE011 and RT reduced phosphorylation of RB in OML1 cells by up to $60 \%$ (Figure 
A

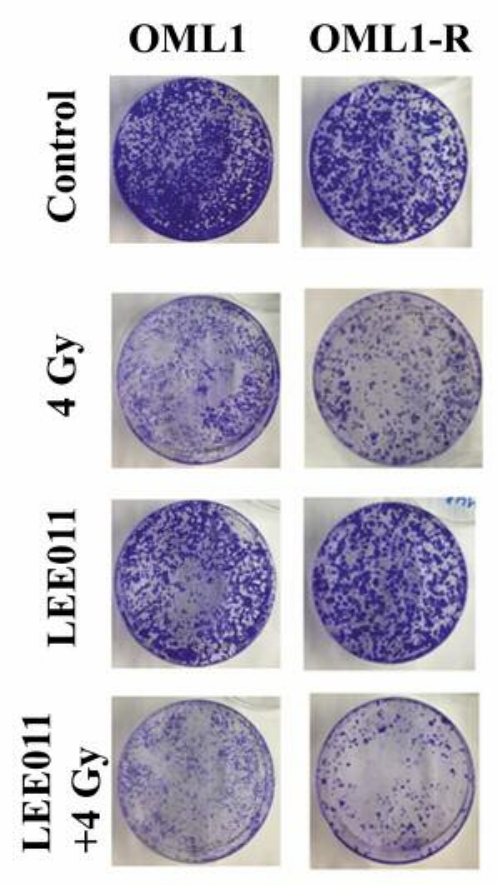

Figure 4. LEE011 enhanced sensitivity to radiotherapy $(R T)$ of head and neck squamous-cell carcinoma cells. OML1 and OML-1 cells were treated with LEEO11 combined with RT. Cells were plated and cultured for 7 days, and colonies (blue area) were stained with $0.05 \%$ crystal violet and analyzed by ImageJ. A: Images were acquired with a digital camera. B: The area of colonies was analyzed and is shown. C: Cells were seeded and cultured for $72 \mathrm{~h}$ for cell proliferation assay, and cell viability was assessed by WST-1 assay. Significantly different at ${ }^{*} p<0.05, * * p<0.01, * * * p<0.001$. ns: Not significant.

6A), and by $80 \%$ in radioresistant OML1-R cells (Figure $6 \mathrm{~B})$. These observations suggest that the inhibition of cellcycle progression seen in human oral cancer cell lines was caused by decrease of RB phosphorylation, which may be due to a loss of CDK4/6 activity. Blocking the cell cycle at the $G_{1}$ phase leads to growth inhibition in oral cancer cells.

\section{Discussion}

RT is a still mainstay treatment modality for HNSCC, but radiation resistance remains a major cause of treatment failure. There are many challenges associated with enhancing radiation damage to tumor tissue, also known as radiation sensitization. Radiosensitizers such as cisplatin and
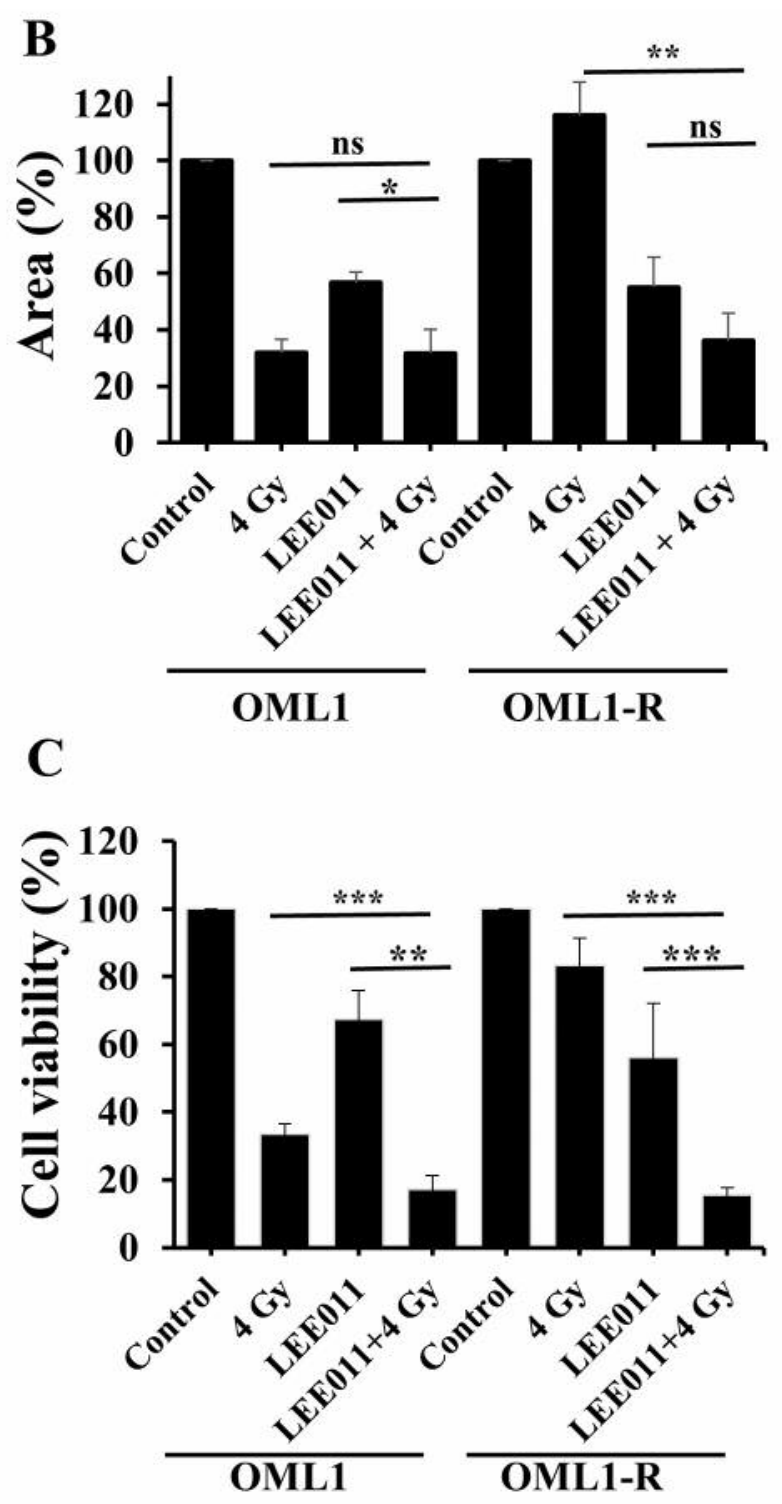

hydroxyurea are typical agents used to enhance injury to tumor tissue by accelerating DNA damage and producing free radicals. Multiple signaling pathways related to apoptosis, metastasis, DNA repair, protein degradation, and others were shown to influence the efficacy of RT [reviewed in (11)]. Recent studies investigating the mechanisms of radioresistance have reported PI3K/AKT/mTOR pathways associated with radiosensitivity (12). Our previous studies identified RAD001 (8), AZD2014 (7), and BEZ235 (6) as potential small-molecule drugs for radiosensitivity, and these three compounds all influence radiation sensitization by the same mechanism, cell-cycle arrest.

The CDK4/6 inhibitor LEE011 is among a new generation of therapeutics. Building upon the striking success of the 

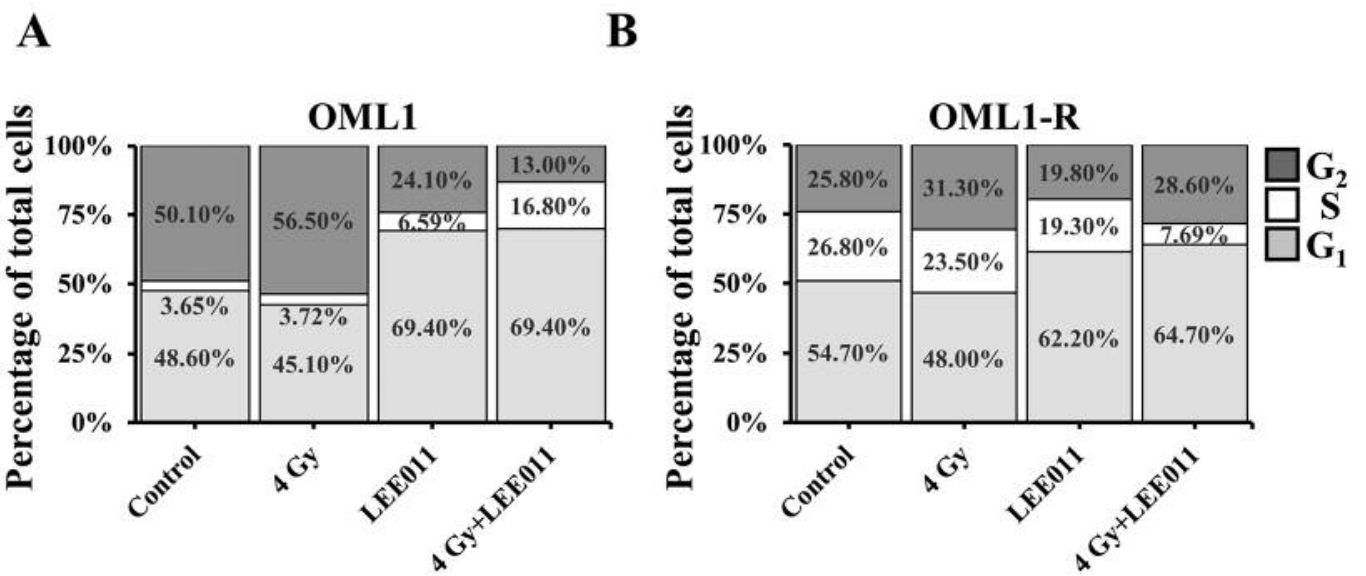

Figure 5. Effect of LEE011 combined with radiotherapy (RT) on cell-cycle progression in head and neck squamous-cell carcinoma cells. OML1 and OML-1 cells were left untreated, treated with LEE011 or with RT alone, or treated with LEE011 combined with RT for 72 h. Cells were harvested and stained with propidium iodide (PI) hypotonic buffer for cell-cycle analysis, and the number indicates the percentage of cells in the cell-cycle phase.

A

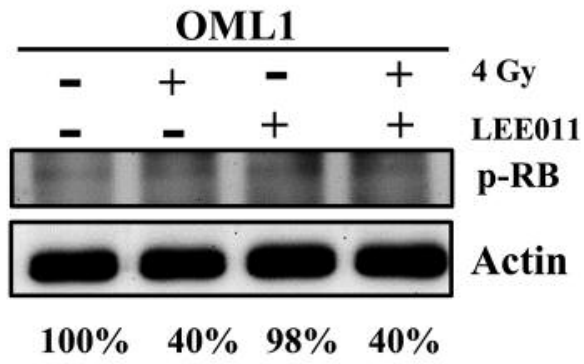

B

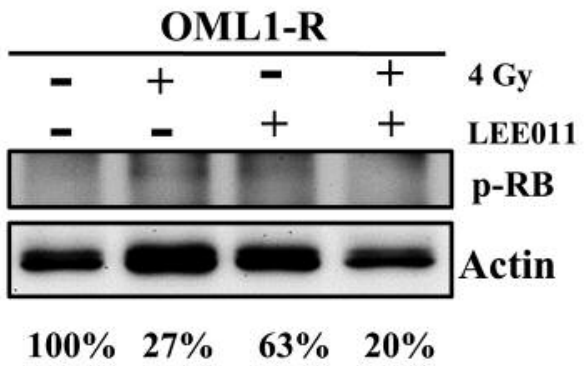

Figure 6. Effect of LEE011 combined with radiotherapy $(R T)$ on retinoblastoma protein (RB phosphorylation in head and neck squamous-cell carcinoma cells. OML1 (A) and RT-resistant cell line OML1-R (B) cells were treated with $100 \mathrm{nM}$ of LEE011 for $72 \mathrm{~h}$ with and without 4 Gy RT. Cell lysates were prepared and analyzed by western blot using antibodies to phosphor-RB (p-RB) and actin. The p-RB band was normalized by actin and the percentage relative to that of the untreated control is shown.

combination of CDK4/6 inhibitors and the hormone receptor antagonist letrozole in breast cancer (13), many other combination therapies have recently entered clinical trials in multiple diseases [reviewed in (14)]. Naz et al. recently reported that the CDK4/6 inhibitor abemaciclib enhanced radiation effects in lung cancer and was a radiosensitizer for lung cancer in preclinical models (15). They found a unique role for CDK4/6 inhibition in radiation-induced vasculogenesis contributing to the enhanced RT response in vivo. Here we report that the radiation sensitization effect is due to cell-cycle arrest in the $\mathrm{G}_{1}$ phase.

The cell cycle is a key factor influencing radiosensitivity, therefore the inhibition of checkpoint kinases in combination with DNA-damaging chemotherapy or RT was proposed as a promising cancer treatment strategy (16). The cell-cycle phase determines the relative radiosensitivity of a cell, and cells are most radiosensitive in the $\mathrm{G}_{2}-\mathrm{M}$ phase, less sensitive in the $G_{1}$ phase, and least sensitive during the latter part of the $\mathrm{S}$ phase. Previous studies have shown that metallic nanoparticles can alter cell-cycle distribution and improve radiosensitivity (17-19), but the clinical application of metallic nanoparticles remains untested. We found that SCC4/SCC25 cell lines were arrested in $\mathrm{G}_{1}$ phase when treated with LEE011, and LEE011 treatment inhibited cell survival of radiation-resistant OML1-R head and neck squamous cells (10). These results confirm that CDK $4 / 6$ inhibition enhances the effects of radiation and can overcome radioresistance in head and neck cell lines. These findings confirm the result of a previous study on non-small cell lung cancer (15), and suggest that the combination of CDK $4 / 6$ 
inhibitor and RT represents a reasonable way to manage patients with HNSCC in advanced disease settings.

By using OML1-R and OML1 cell lines, we created a model to test the radiosensitization effects of various drugs in HNSCC $(6-8,10)$. We had previously explored the radiosensitization effects of $\mathrm{PI} 3 \mathrm{~K} / \mathrm{mTOR} / \mathrm{CDK}$ inhibition and demonstrated that the most important mechanism is cell-cycle arrest. CDK4/6 appears to be the most efficient and least toxic target, but its clinical application still needs further investigation in clinical trials. Currently, chemotherapeutic agents such as cetuximab, cisplatin, and fluoruracil are the most popular drugs approved for clinical use in concurrent chemotherapy combined with RT for head and neck cancer (3). These drugs have been wellinvestigated for their safety and pharmacokinetic properties, and although it may be more convenient to introduce them into clinical application, more toxic effects were reported in the groups treated with concurrent chemotherapy combined with RT (20). There are also reports investigating other small-molecule agents, such as hypoxic radiosensitizers (21) tirapazamine (22) and nimorazole (23), but the trials failed to identify evidence of an overall survival benefit. Our study suggested the possibility of $\mathrm{PI} 3 \mathrm{~K} / \mathrm{mTOR} / \mathrm{CDK}$ inhibitor usage in concurrent chemotherapy combined with RT settings, leading to a new method of treatment for advanced/recurrent HNSCC.

\section{Conflicts of Interests}

The Author(s) declared no potential conflicts of interest with respect to the research, authorship, or publication of this article.

\section{Acknowledgements}

The study was supported by the funding from E-DA hospital (Grant number: EDAHI106004, EDPJ104055, EDAHT106034 and EDAHT106040).

\section{References}

1 Cohen N, Fedewa $\mathrm{S}$ and Chen AY: Epidemiology and demographics of the head and neck cancer population. Oral Maxillofac Surg Clin North Am 30(4): 381-395, 2018.

2 Pignon JP, Bourhis J, Domenge $\mathrm{C}$ and Designe L: Chemotherapy added to locoregional treatment for head and neck squamous-cell carcinoma: Three meta-analyses of updated individual data. Mach-NC Collaborative Group. Metaanalysis of chemotherapy on head and neck cancer. Lancet 355(9208): 949-955, 2000.

3 Winquist E, Agbassi C, Meyers BM, Yoo J, Chan KKW, Head and Neck Disease Site Group: Systemic therapy in the curative treatment of head and neck squamous cell cancer: A systematic review. J Otolaryngol Head Neck Surg 46(1): 29, 2017.

4 Willems L, Tamburini J, Chapuis N, Lacombe C, Mayeux P and Bouscary D: Pi3k and mTOR signaling pathways in cancer: New data on targeted therapies. Curr Oncol Rep 14(2): 129-138, 2012.
5 Ahmad A, Biersack B, Li Y, Kong D, Bao B, Schobert R, Padhye SB and Sarkar FH: Deregulation of PI3K/AKT/mTOR signaling pathways by isoflavones and its implication in cancer treatment. Anticancer Agents Med Chem 13(7): 1014-1024, 2013.

6 Yu CC, Hung SK, Lin HY, Chiou WY, Lee MS, Liao HF, Huang HB, Ho HC and Su YC: Targeting the PI3K/AKT/mTOR signaling pathway as an effectively radiosensitizing strategy for treating human oral squamous cell carcinoma in vitro and in vivo. Oncotarget 8(40): 68641-68653, 2017.

7 Yu CC, Huang HB, Hung SK, Liao HF, Lee CC, Lin HY, Li SC, Ho HC, Hung CL and Su YC: AZD2014 radiosensitizes oral squamous cell carcinoma by inhibiting AKT/mTOR axis and inducing $\mathrm{G}_{1} / \mathrm{G}_{2} / \mathrm{M}$ cell cycle arrest. PLoS One 11(3): e0151942, 2016.

8 Yu CC, Hung SK, Liao HF, Lee CC, Lin HY, Lai HC, Li SC, Ho $\mathrm{HC}$, Huang $\mathrm{HB}$ and Su YC: Rad001 enhances the radiosensitivity of SCC4 oral cancer cells by inducing cell cycle arrest at the $\mathrm{G}_{2} / \mathrm{M}$ checkpoint. Anticancer Res 34(6): 2927-2935, 2014.

9 American Association for Cancer Research: News in Brief: Targeting mutant AKT in cancer. Cancer Discov 6(1): OF7, 2016. doi: 10.1158/2159-8290.CD-NB2015-16

10 Lin HY, Hung SK, Lee MS, Chiou WY, Huang TT, Tseng CE, Shih LY, Lin RI, Lin JM, Lai YH, Chang CB, Hsu FC, Chen LC, Tsai SJ, Su YC, Li SC, Lai HC, Hsu WL, Liu DW, Tai CK, Wu SF and Chan MW: DNA methylome analysis identifies epigenetic silencing of FHIT as a determining factor for radiosensitivity in oral cancer: An outcome-predicting and treatment-implicating study. Oncotarget 6(2): 915-934, 2015.

11 Wang $\mathrm{H}, \mathrm{Mu} \mathrm{X}, \mathrm{He} \mathrm{H}$ and Zhang XD: Cancer radiosensitizers. Trends Pharmacol Sci 39(1): 24-48, 2018.

12 Wang Z, Huang Y and Zhang J: Molecularly targeting the PI3KAKT-mTOR pathway can sensitize cancer cells to radiotherapy and chemotherapy. Cell Mol Biol Lett 19(2): 233-242, 2014.

13 Janni W, Alba E, Bachelot T, Diab S, Gil-Gil M, Beck TJ, Ryvo L, Lopez R, Tsai M, Esteva FJ, Aunon PZ, Kral Z, Ward P, Richards P, Pluard TJ, Sutradhar S, Miller M and Campone M: First-line ribociclib plus letrozole in postmenopausal women with HR+, HER2- advanced breast cancer: Tumor response and pain reduction in the phase 3 MONALEESA-2 trial. Breast Cancer Res Treat 169(3): 469-479, 2018.

14 Klein ME, Kovatcheva M, Davis LE, Tap WD and Koff A: CDK4/6 inhibitors: The mechanism of action may not be as simple as once thought. Cancer Cell 34(1): 9-20, 2018.

$15 \mathrm{Naz}$ S, Sowers A, Choudhuri R, Wissler M, Gamson J, Mathias A, Cook JA and Mitchell JB: Abemaciclib, a selective CDK4/6 inhibitor, enhances the radiosensitivity of non-small cell lung cancer in vitro and in vivo. Clin Cancer Res, 2018.

16 Zhou BB and Bartek J: Targeting the checkpoint kinases: Chemosensitization versus chemoprotection. Nat Rev Cancer 4(3): 216-225, 2004.

17 Pawlik TM and Keyomarsi K: Role of cell cycle in mediating sensitivity to radiotherapy. Int J Radiat Oncol Biol Phys 59(4): 928-942, 2004.

18 Liu Y, Chen W, Zhang P, Jin X, Liu X, Li P, Li F, Zhang H, Zou $\mathrm{G}$ and $\mathrm{Li} \mathrm{Q}$ : Dynamically-enhanced retention of gold nanoclusters in HeLa cells following X-rays exposure: A cell cycle phase-dependent targeting approach. Radiother Oncol 119(3): 544-551, 2016. 
19 Roa W, Zhang X, Guo L, Shaw A, Hu X, Xiong Y, Gulavita S, Patel S, Sun X, Chen J, Moore R and Xing JZ: Gold nanoparticle sensitize radiotherapy of prostate cancer cells by regulation of the cell cycle. Nanotechnology 20(37): 375101, 2009.

20 Tobias JS, Monson K, Gupta N, Macdougall H, Glaholm J, Hutchison I, Kadalayil L, Hackshaw A, Head UK and Neck Cancer Trialists G: Chemoradiotherapy for locally advanced head and neck cancer: 10-Year follow-up of the UK head and neck (UKHAN1) trial. Lancet Oncol 11(1): 66-74, 2010.

21 Zackrisson B, Nilsson P, Kjellen E, Johansson KA, Modig H, Brun E, Nyman J, Friesland S, Reizenstein J, Sjodin H, Ekberg L, Loden B, Mercke C, Fernberg JO, Franzen L, Ask A, Persson E, Wickart-Johansson G, Lewin F, Wittgren L, Bjor O and Bjork-Eriksson T: Two-year results from a Swedish study on conventional versus accelerated radiotherapy in head and neck squamous cell carcinoma-the ARTSCAN study. Radiother Oncol 100(1): 41-48, 2011.
22 Rischin D, Peters LJ, O’Sullivan B, Giralt J, Fisher R, Yuen K, Trotti A, Bernier J, Bourhis J, Ringash J, Henke M and Kenny L: Tirapazamine, cisplatin, and radiation versus cisplatin and radiation for advanced squamous cell carcinoma of the head and neck (TROG 02.02, headstart): A phase III trial of the Trans-Tasman Radiation Oncology Group. J Clin Oncol 28(18): 2989-2995, 2010.

23 Hassan Metwally MA, Jansen JA and Overgaard J: Study of the population pharmacokinetic characteristics of nimorazole in head and neck cancer patients treated in the DAHANCA-5 trial. Clin Oncol 27(3): 168-175, 2015.
Received December 10, 2018

Revised December 19, 2018

Accepted December 20, 2018 